\title{
Anti-oxidant and anti-hyperlipidemic effects of cordycepin-rich Cordyceps militaris in a Sprague-Dawley rat model of alcohol-induced hyperlipidemia and oxidative stress
}

\author{
Hee-Young Ahn ${ }^{1}$, Hyun-Dong Cho ${ }^{2}$ and Young-Su Cho ${ }^{*}$ (i)
}

\begin{abstract}
Hyperlipidemia is involved in serious cardiovascular disease, however, synthetic drugs to reduce lipid contents in blood stream have been found to induce serious side effects. In the current study, we compared anti-oxidant and anti-hyperlipidemic effect of Paecilomyces japonica (PJ), Cordyceps militaris (CM) and cordycepin-rich Cordyceps militaris $(\mathrm{CMa})$ in rats induced alcoholic hyperlipidemia $(\mathrm{AlH})$ and oxidative stress. The experimental groups were divided in $\mathrm{N}$ (water), C (30\% alcohol), PJ (30\% alcohol + 3\% PJ powder), CM (30\% alcohol +3\% CM powder), CMa (30\% alcohol $+3 \%$ CMa powder) and SM [30\% alcohol + $0.1 \%$ silymarin (SM)]. Compared to C group, supplementation of PJ, CM, CMa and SM slightly alleviated the increased weight ratio of liver and kidney in the alcohol-treated rats. In addition, a significant or slight reduction was identified in total lipid, total cholesterol and HDL-cholesterol levels in the rats receiving PJ, CM and CMa as compared with C group. Administration of PJ, CM and CMa also blocked alcohol-induced lipid peroxidation via a decrease of malondialdehyde (MDA), and activated anti-oxidant enzyme, glutathione (GSH), in serum and various organ tissues. Overall, cordycepin-rich CMa showed highest anti-oxidant and anti-hyperlipidemia effect under chronic alcoholic damage. Our results indicate that CMa might be useful in inhibiting the oxidation and hyperlipidemia in alcohol-induced hepatic disease possibly because of potential anti-oxidative and anti-hyperlipidemic activities of cordycepin.
\end{abstract}

Keywords: Cordycepin-rich Cordyceps militaris, Thiobarbituric acid-reactive substances (TBARS), Reduced glutathione (GSH), Oxidative stress, Anti-hyperlipidemic activity

\section{Introduction}

Hyperlipidemia, known as the condition of abnormally increased lipid in plasma and tissues, is a potential risk factor resulting in atherosclerosis and cardiovascular diseases (AlHajri et al. 2017). During a decade, numerous studies have focused on the importance of

\footnotetext{
*Correspondence: choys@dau.ac.kr

${ }^{1}$ Department of Biotechnology, Dong-A University, 225 Gudeok-ro

Seo-gu, Busan 49315, South Korea

Full list of author information is available at the end of the article
}

regulating lipid profile to prevent coronary heart disease, cerebral stroke, myocardial infarction, diabetes and renal failure. In addition, these kinds of risk factors can aggravate pathological condition to induce oxidative damage at the molecular level (Nagarthna et al. 2020). However, chemotherapeutics lowering lipid level have been found to cause serious adversary effects, such as, depression, anxiety, headache, nausea, diarrhea, vomiting, cardiac toxicity and constipation (Niharika 2017). Thus, in recent years, there has been growing interest in the development of less toxic 
anti-hyperlipidemia agent using natural product and its bioconversion process.

Cordycepin, 3-deoxyadenosine, is a derivative of the nucleoside adenosine, and it is abundantly present in Cordyceps species (Ju et al. 2009; Zhou et al. 2016). Since cordycepin shows chemical similarity to adenosine, it could be involved in the incorporation of RNA molecule causing a broad range of biological activities (Chen et al. 2017). Furthermore, tremendous evidences have reported its anticancer, anti-hypertension, antiliver injury and improving immune response effects (Jing et al. 2015; Chen et al. 2017). Therefore, the consumption of Cordyceps species has steadily increased with the expectation of positive effect on chronic diseases.

Cordyceps militaris (C. militaris, CM) and Paecilomyces japonica (P. japonica, PJ) belong to the Cordyceps species, and they are produced by silkworm inoculated with different fungal parasites. $\mathrm{CM}$ is a mushroom that is widely present worldwide and has long been used as a nutraceutical and traditional medicine in the eastern Asia (Jing et al. 2015), and PJ is used as a dietary supplement that is effective in improving stamina, blood circulation and the quality of life (Shin et al. 2003; Shin et al. 2001). To date, numerous attempts have been made to identify a novel type of cordycepin-rich Cordyceps species (Guo et al. 2010; Sun et al. 2011). Previous studies have demonstrated that cross-bred cordycepin-rich $\mathrm{CM}(\mathrm{CM} \alpha)$ (JLM 0636) had a sevenfold larger amount of cordycepin (742 mg/100 g d.w.) as compared with normal CM (Cha et al. 2011). Moreover, it was 1.7-24.7 times larger as compared with CM (448 mg/100 g d.w.), Cordyceps sinensis (30 mg/100 g d.w.) and PJ (54 mg/100 g d.w.) (Oh et al. 2003). Furthermore, we have also previously demonstrated simple screening on effectiveness of CM, PM and CM $\alpha$ in a Sprague-Dawley (SD) model of orotic acid-induced hepatotoxicity and oxidative stress (OS) (Cha et al. 2011). Still, however, there is a paucity of data regarding the biological effects of CM $\alpha$ in an SD model of alcohol-induced hyperlipidemia (AIH) and OS.

Given the above background, this study conducted this experimental study to examine anti-oxidant and antihyperlipidemic effects of $\mathrm{CM} \alpha$ as compared with $\mathrm{CM}$ and $\mathrm{PJ}$ in an SD model of AIH and OS.

\section{Materials and methods Materials}

The dried fruiting bodies of PJ, CM and CM $\alpha$ were purchased from a commercial supplier (Chungwonnonsan Co., Ltd., Gimhae, Korea). In addition, the cordycepin standard (purity $>95 \%$; Cat No. PHL82505) was purchased from Sigma Chemical Co. (St. Louis, MO, USA).

\section{Experimental animals and design}

A total of 36 male SD rats (Hyochang Science Animals Co., Daegu, Korea) were housed individually at room temperature $\left(21-24{ }^{\circ} \mathrm{C}\right)$ under a 12-h light/12-h dark cycle. For a week before the experimental procedure, they were provided with food and water ad libitum. Then, they were randomly divided into the following 6 experimental groups (Additional file 1):

1. The Group N $(n=6)$ : The normal SD rats receiving water

2. The Group C ( $n=6)$ : The SD rats receiving $30 \%$ alcohol

3. The Group PJ ( $n=6)$ : The SD rats receiving 30\% alcohol $+3 \%$ PJ powder

4. The Group CM $(n=6)$ : The SD rats receiving $30 \%$ alcohol $+3 \%$ CM powder

5. The Group CM $\alpha(n=6)$ : The SD rats receiving 30\% alcohol $+3 \%$ CM $\alpha$ powder

6. The Group SM $(n=6)$ : The SD rats receiving $30 \%$ alcohol $+0.1 \%$ silymarin $(\mathrm{SM})$.

The amount of PJ, CM, CM $\alpha$ and SM supplemented to the diet was determined as previously described (Koh and Choi 2003; Dahiru and Obidoa 2007). The food consumption and water intake were measured every day and body weight gain was measured once a week. The current experimental study was conducted in accordance with the National Institute of Health guidelines on the care and use of laboratory animals, and it was approved by the Institutional Animal Care and Use Committee (IACUC) of our institution (IACUC approval \# 160/1999/ CPCSEA).

\section{Measurement of lipid levels}

After 4 weeks, the SD rats were killed by withdrawing blood from the abdominal aorta under light diethyl ether anesthesia. The serum sample was obtained by the centrifugation of the blood at $1026 \times g$ for $15 \mathrm{~min}$ at $4{ }^{\circ} \mathrm{C}$. The concentrations of serum total lipid, triglyceride (TG), total cholesterol (TC), high-density lipoprotein- (HDL)cholesterol and non-esterified free acid (NEFA) were measured using the Chemiclinical Chemistry Analyzer (Neodin Medicinal Institute, Seoul, Korea). Hepatic lipid was extracted, as previously described (Folch et al. 1957). Hepatic TG levels were enzymatically measured using a commercial kit (Sigma Chemical Co.), which is based on a modification of the lipase-glycerol phosphate oxidase method (McGowan et al. 1983).

Measurement of lipid peroxidation and glutathione levels The organs such as liver, kidney, heart, spleen and testis were quickly removed, weighted and then kept in a plastic 
bag at $-70{ }^{\circ} \mathrm{C}$. This was followed by the preparation of tissue homogenates and hepatic subcellular fractions as previously described (Cha et al. 2001). In addition, protein contents of the liver homogenate and cellular fractions were measured by the method of Lowry et al. (1951). The lipid peroxidation products were estimated by measuring thiobarbituric acid-reactive substances (TBARS), as previously described (Ohkawa et al. 1979). The concentration of TBARS was expressed as nmol of malondialdehyde (MDA) per g tissues or $\mathrm{mL}$ serum. The concentration of glutathione (GSH), nonenzymatic antioxidant, was determined as previously described (Beutler et al. 1963). It was expressed as $\mathrm{mg} / \mathrm{g}$ tissue and $\mathrm{mg} / \mathrm{mL}$ serum.

\section{Statistical analysis}

Statistical analysis was done using the SPSS 17.0 for Windows (SPSS Inc., Chicago, IL). All data were expressed as the mean \pm SEM (SEM: standard errors of the mean). Data analysis was performed using one-way analysis of variance (ANOVA), followed by a post hoc analysis using the Duncan's new multiple-range test. A $P$ value of $<0.05$ was considered statistically significant.

\section{Results}

Effect of PJ, CM, CMa and SM on body and organ weight in the alcohol-treated SD rats

As shown in Table 1, although the initial body weight was not significant in normal, control, PJ, CM, CM $\alpha$ and $\mathrm{SM}$, there was a statistically meaningful decrease of the final body weight in C, PJ, CM, CM $\alpha$ and SM. Compared to $\mathrm{N}$ group, $\mathrm{C}$ group showed markedly increased tissue weight by $0.51 \%, 0.08 \%$ and $0.05 \%$ in liver, kidney and testis, respectively, and decreased perirenal and epididymal fat weight by $0.72 \%$ and $0.42 \%$, respectively. Compared to control group, administration of PJ, CM, CM $\alpha$ and SM slightly alleviated the increased weight ratio of liver and kidney in alcohol-treated rats. However, there was no specific correlation in weight of heart, spleen, testis, perirenal fat and epididymal fat between N, C, PJ, CM and $\mathrm{CM} \alpha$ group.

\section{Effect of PJ, CM, CMa and SM on serum and liver lipid profile in the alcohol-treated SD rats}

In comparison with normal group, there were significant increase of liver and serum TG levels in the SD rats receiving alcohol (control group) (Fig. 1). However, administration of PJ, CM, CM $\alpha$ and SM markedly decreased liver and serum TG contents. It is noteworthy that there was no significant difference in serum and liver levels of TG between the SD rats receiving $\mathrm{CM} \alpha$ and normal ones (Fig. 1). There was no significant difference in serum levels of total lipid, TC, HDL-cholesterol and NEFA between normal and control groups (Table 2). But there was a significant or slight decrease in total lipid, total cholesterol and HDL-cholesterol levels in the rats receiving PJ, CM and $\mathrm{CM} \alpha$ as compared with those receiving alcohol only. Treatment of SM, positive control for hyperlipidemia, significantly improved lipid condition compared to control rats; it showed no significant difference from normal rats. There was a slight improvement in lipid conditions in the SD rats receiving $\mathrm{CM} \alpha$; total cholesterol and HDL-cholesterol levels showed no significant difference from the SD rats receiving the SM.

\section{Effect of PJ, CM, CMa and SM on MDA and GSH levels in the alcohol-treated SD rats}

There was a significant or slight increase in MDA levels in the serum, hepatic subcellular fractions, kidney, heart, spleen and testis in the SD rats receiving alcohol only as compared with normal ones. But a significant decrease in MDA levels was observed in the serum, hepatic subcellular fractions, kidney, heart, spleen and testis in the SD rats receiving $\mathrm{CM} \alpha$. Although $\mathrm{PJ}$ and

Table 1 Body weight and the relative weight of the tissue $(\%)^{1}$ in the rats receiving alcohol

\begin{tabular}{|c|c|c|c|c|c|c|}
\hline & $\mathrm{N}$ & $C$ & PJ & CM & CMa & SM \\
\hline Initial body weight (g) & $167.7 \pm 2.95^{\mathrm{a}}$ & $167.2 \pm 3.25^{\mathrm{a}}$ & $166.1 \pm 2.48^{\mathrm{a}}$ & $166.0 \pm 2.25^{a}$ & $164.8 \pm 1.86^{\mathrm{a}}$ & $164.8 \pm 1.86^{a}$ \\
\hline Final body weight (g) & $407.3 \pm 10.9^{a}$ & $342.7 \pm 7.78^{b}$ & $327.3 \pm 11.0^{c}$ & $349.0 \pm 9.81^{b c}$ & $326.9 \pm 16.7^{b c}$ & $356.7 \pm 10.4^{b c}$ \\
\hline Liver (\%) & $3.05 \pm 0.20^{\mathrm{ac}}$ & $3.56 \pm 0.20^{b}$ & $2.86 \pm 0.07^{\mathrm{ac}}$ & $2.67 \pm 0.13^{\mathrm{a}}$ & $3.12 \pm 0.09^{c}$ & $2.91 \pm 0.12^{\mathrm{ac}}$ \\
\hline Kidney (\%) & $0.69 \pm 0.01^{a}$ & $0.77 \pm 0.03^{b c}$ & $0.71 \pm 0.02^{\mathrm{ac}}$ & $0.68 \pm 0.01^{a}$ & $0.81 \pm 0.05^{b}$ & $0.73 \pm 0.02^{\mathrm{ac}}$ \\
\hline Heart (\%) & $0.35 \pm 0.01^{a}$ & $0.36 \pm 0.01^{a}$ & $0.37 \pm 0.01^{a}$ & $0.36 \pm 0.01^{\mathrm{a}}$ & $0.36 \pm 0.01^{\mathrm{a}}$ & $0.36 \pm 0.01^{a}$ \\
\hline Spleen (\%) & $0.21 \pm 0.01^{a}$ & $0.21 \pm 0.01^{a}$ & $0.25 \pm 0.01^{b c}$ & $0.22 \pm 0.01^{\mathrm{ac}}$ & $0.27 \pm 0.02^{b}$ & $0.20 \pm 0.01^{a}$ \\
\hline Testis (\%) & $0.94 \pm 0.03^{a}$ & $0.99 \pm 0.03^{a b}$ & $1.11 \pm 0.03^{b}$ & $0.96 \pm 0.05^{a}$ & $1.12 \pm 0.04^{b}$ & $1.02 \pm 0.06^{\mathrm{ab}}$ \\
\hline Perirenal fat (\%) & $2.26 \pm 0.14^{a}$ & $1.54 \pm 0.15^{b}$ & $1.53 \pm 0.14^{b}$ & $1.47 \pm 0.09^{b}$ & $1.15 \pm 0.06^{b}$ & $1.43 \pm 0.16^{b}$ \\
\hline Epididymal fat (\%) & $2.18 \pm 0.18^{a}$ & $1.76 \pm 0.10^{b c}$ & $1.87 \pm 0.16^{\mathrm{ac}}$ & $1.61 \pm 0.06^{b c}$ & $1.43 \pm 0.05^{b}$ & $1.58 \pm 0.14^{b c}$ \\
\hline
\end{tabular}

$\mathrm{N}$, normal; C, control; PJ, Psoroglaena japonica; CM, Cordyceps militaris; CMa, cordycepin-rich C. militaris; SM, syrimarin

1 The relative weight of the tissue (\%) represents the ratio of the tissue weight to the body weight 

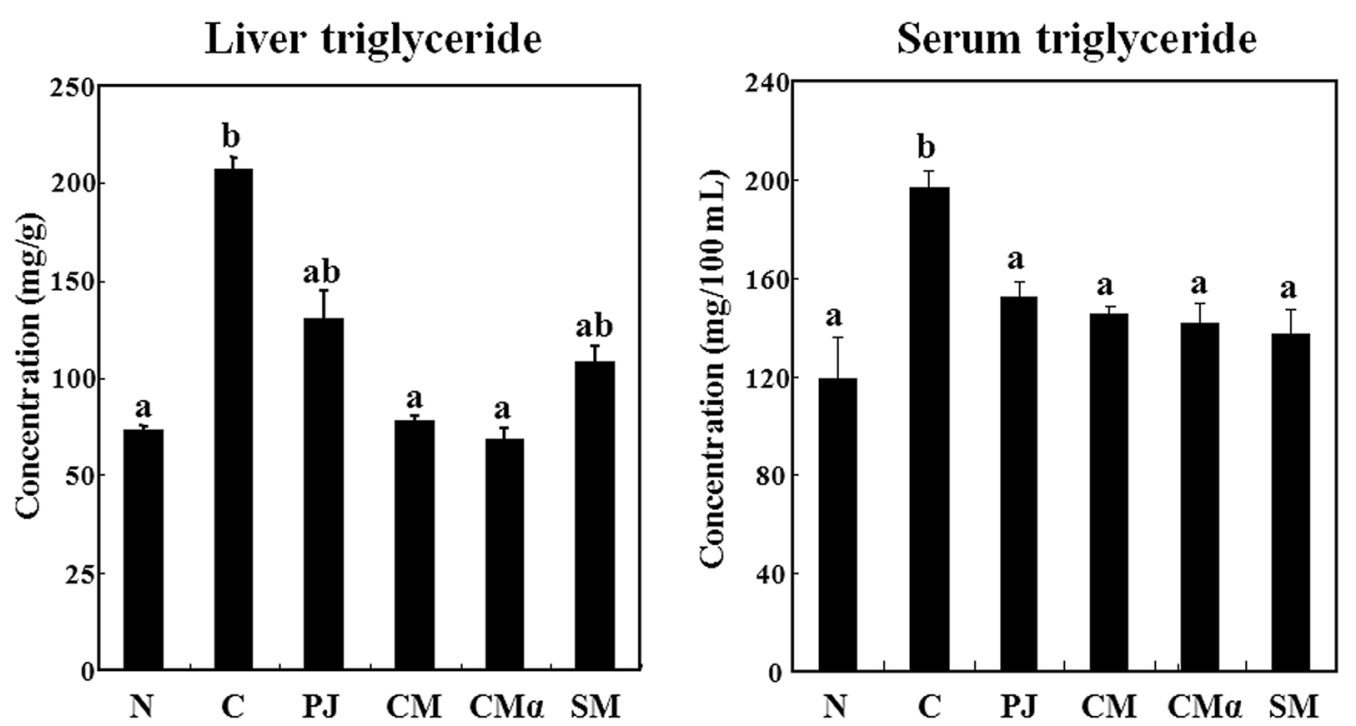

Fig. 1 Hepatic and serum levels of triglyceride

Table 2 Serum lipid levels in the rats receiving alcohol

\begin{tabular}{lllll}
\hline Group & Total lipid $\mathbf{( m g / 1 0 0 ~} \mathbf{~ L L})$ & $\begin{array}{l}\text { Nonesterified fatty acid } \\
(\mathbf{m m o l} / \mathbf{L})\end{array}$ & $\begin{array}{l}\text { Total cholesterol } \\
(\mathbf{m g} / \mathbf{1 0 0} \mathbf{~ m L})\end{array}$ & $\begin{array}{l}\text { HDL-cholsterol } \\
(\mathbf{m g} / \mathbf{1 0 0} \mathbf{~ m L})\end{array}$ \\
\hline N & $367.3 \pm 24.9^{\mathrm{ab}}$ & $1.06 \pm 0.04^{\mathrm{a}}$ & $65.17 \pm 5.40^{\mathrm{a}}$ & $32.20 \pm 0.65^{\mathrm{a}}$ \\
C & $398.1 \pm 18.0^{\mathrm{a}}$ & $1.13 \pm 0.15^{\mathrm{ab}}$ & $93.17 \pm 7.39^{\mathrm{b}}$ & $34.40 \pm 1.67^{\mathrm{a}}$ \\
PJ & $365.8 \pm 25.2^{\mathrm{ab}}$ & $1.33 \pm 0.06^{\mathrm{b}}$ & $70.14 \pm 1.71^{\mathrm{a}}$ & $28.04 \pm 0.42^{\mathrm{b}}$ \\
CM & $357.1 \pm 12.7^{\mathrm{ab}}$ & $1.36 \pm 0.08^{\mathrm{b}}$ & $70.00 \pm 2.14^{\mathrm{a}}$ & $28.86 \pm 0.46^{\mathrm{b}}$ \\
CMa & $356.0 \pm 15.1^{\mathrm{ab}}$ & $1.34 \pm 0.07^{\mathrm{b}}$ & $69.00 \pm 6.55^{\mathrm{a}}$ & $29.50 \pm 1.26^{\mathrm{b}}$ \\
SM & $315.0 \pm 19.0^{\mathrm{b}}$ & $1.02 \pm 0.05^{\mathrm{a}}$ & $71.17 \pm 7.82^{\mathrm{a}}$ & $28.50 \pm 2.31^{\mathrm{b}}$ \\
\hline
\end{tabular}

Values are mean \pm S.E. (S.E.: standard error of the mean). Different letters indicate significant differences between the groups $(P<0.05)$

$\mathrm{N}$, normal; C, control; PJ, Psoroglaena japonica; CM, Cordyceps militaris; CMa, cordycepin-rich C. militaris; SM, syrimarin

$\mathrm{CM}$ administration indicated a reducing tendency of MDA levels, CM $\alpha$ showed lowest MDA contents in the serum, hepatic subcellular fractions, kidney, heart, spleen and testis (Figs. 2, 3). Treatment of SM significantly down-regulated MDA contents in lipid condition in the serum, hepatic subcellular fractions, kidney, heart, spleen and testis, compared to control rats.

Furthermore, a significant increase of GSH levels were indicated in the serum, liver, kidney, heart, spleen and testis in control rats as compared with normal ones. Similarly with MDA results, CM $\alpha$-treated rats showed highest GSH levels in the serum, liver, kidney, heart, spleen and testis, compared to control ones (Fig. 4). Rats administered with SM markedly increased GSH levels in liver, serum, testis and spleen, however, kidney and heart were not affected by SM treatment.

\section{Discussion}

A number of studies have reported that periodic alcohol consumption is closely involved with fatty liver, obesity, diabetes and hepatic steatosis (Volzke 2012). In the present study, a continuous consumption of alcohol (4 weeks) inhibited the normal growth of the rats; this is well illustrated in a decreased body weight and increased liver weight in the rats receiving alcohol only as compared with normal ones. Although administration of CM $\alpha$ lowered body weight more than control rats, PM- and CMserved rats, CM $\alpha$ treatment significantly recovered fatty liver symptom which is induced by alcoholic damage. A previous study also demonstrated that the administration of water extract from $P$. tenuipes in high-fat induced obesity mice produced a significantly lower body weight gain and fatty liver (Heo et al. 2009). In addition, Guo et al. also found that cordycepin was effective in not only 

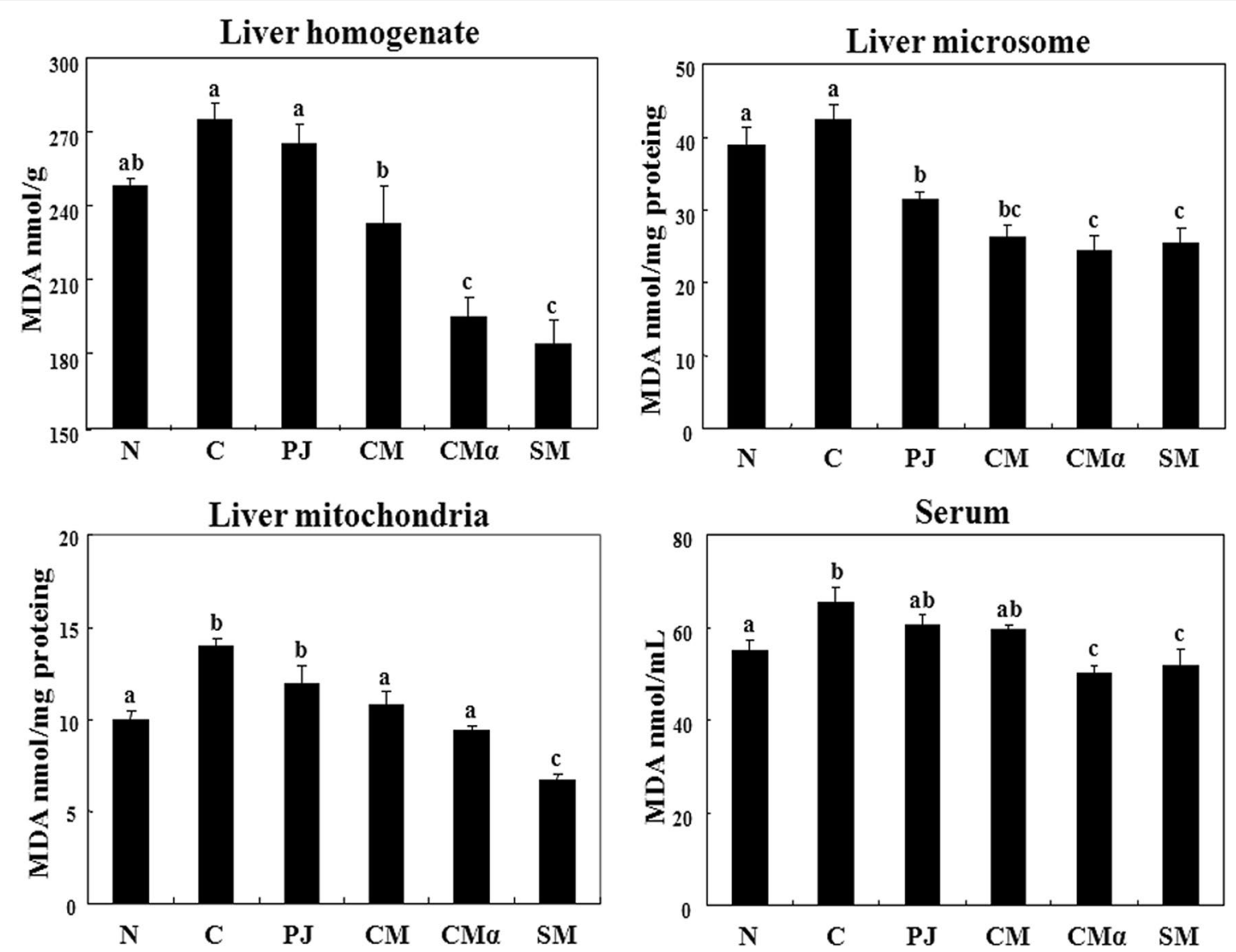

Fig. 2 Hepatic and serum levels of thiobarbituric acid-reactive substances (TBARS)

reducing the body weight gain and the relative amount of the retroperitoneal fat, but also markedly decreasing lipid droplets in liver tissue when administered to hamsters at a dose of $50 \mathrm{mg} / \mathrm{kg}$ for 2 weeks (Guo et al. 2010). These findings suggest that supplementation of cordycepin-rich Cordyceps militaris during alcohol consumption causes effect of weight loss and fatty liver prevention.

Chronic heavy drinking causes serious liver problems such as fatty liver, alcoholic hepatitis and cirrhosis. They are collectively called alcohol-related liver disease that is characterized by hepatic TG accumulation (Tahara et al. 1999). It is also seen in our previous finding and present result showing that consumption of alcohol increases hepatic TG level in the SD rats (Cha et al. 2011; Additional file 2, Table 1, Fig. 1). This is in agreement with a previous report that there was a fourfold increase in hepatic TG levels after alcohol supplementation (Oliva et al. 1998). In the current study, SD rats receiving CM and CM $\alpha$ showed significant lower hepatic TG as compared with control ones. Our study also found that a slight decrease of hepatic TG levels indicated in the SD rats receiving $\mathrm{PJ}$ and SM. It is noteworthy that $\mathrm{CM} \alpha$ had a higher effect on reducing lipid accumulation in the liver as compared with the SM, one of the well-known hepatoprotective agents. These findings showed similarity with previous reports demonstrating fatty liver preventative effect of vegetable worms (Koh and Choi 2003; Han et al. 2009). In addition, Guo et al. showed that cordycepin markedly decreased the proportion of lipid droplets in the liver by Oil-Red O stain, thus suggesting that it plays a role in preventing lipid accumulation in the liver (Guo et al. 2010). These results indicate that cordycepin-rich $\mathrm{CM} \alpha$ can effectively block alcohol-induced lipid accumulation in liver.

Alcohol consumption is a powerful factor that induces hyperlipidemia in both animals and humans (Singh et al. 2016). It has been suggested that the most common lipid abnormalities during chronic alcohol consumption are known to produce hypercholesterolemia and hypertriglyceridemia (Bessembinders et al. 2011). In the current study, a significant decrease was observed in serum TG levels in the SD rats receiving PJ, CM, CM $\alpha$ and SM as compared with those receiving alcohol only. According to Koh and Choi, there was a significant decrease in serum 

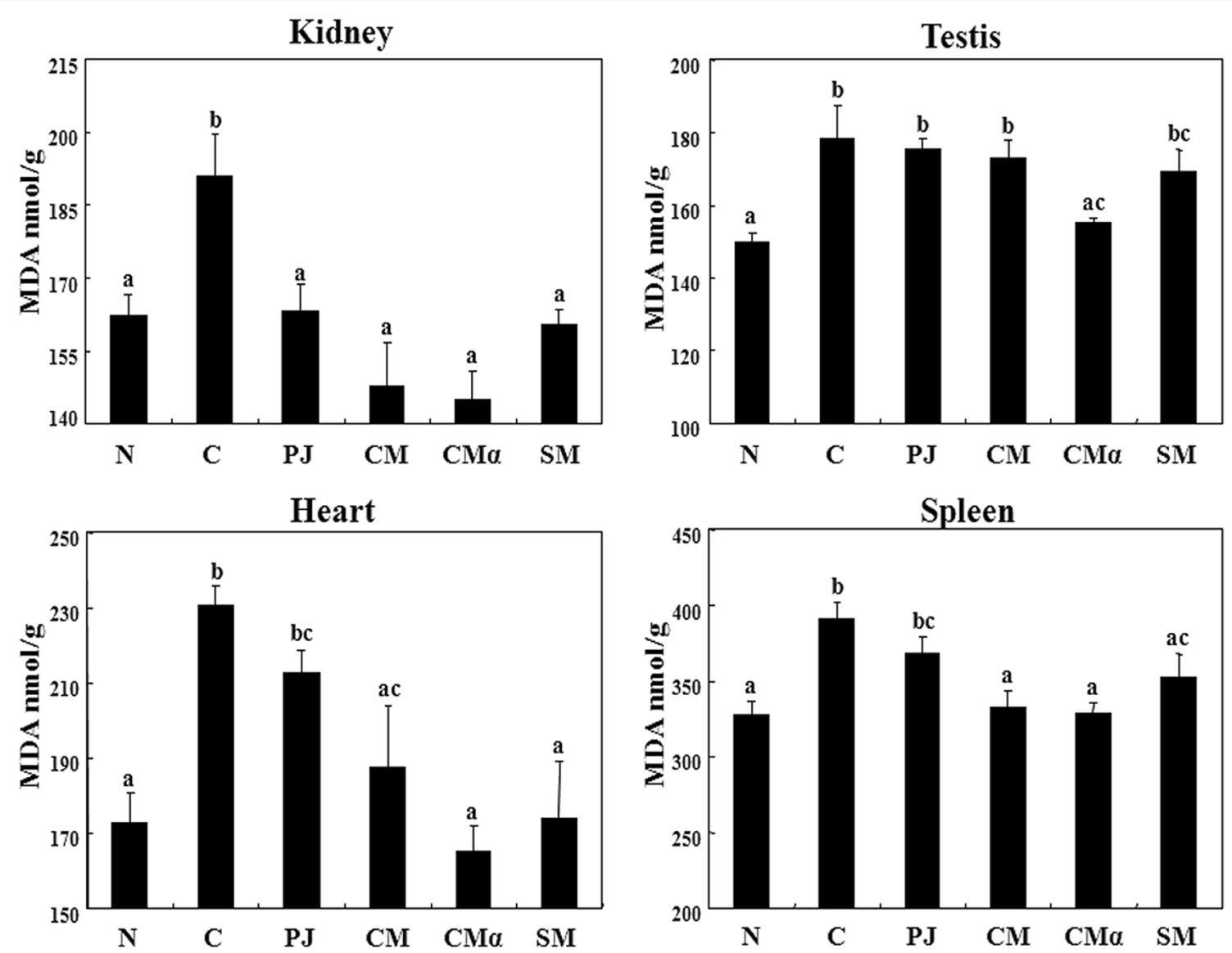

Fig. 3 Concentrations of thiobarbituric acid-reactive substances (TBARS) in kidney, heart, spleen and testis

TG levels after treatment of 3\% PJ in high-fat feeding rats (Koh and Choi 2003). Moreover, Han et al. also reported that a significant decrease in serum TG levels was identified after treatment with 6\% PJ (Han et al. 2009). Furthermore, most of the studies in this series have reported the serum TC levels is increased due to heavy alcohol consumption, and disruption of cholesterol metabolism (Saini et al. 2019; El-Tantawy and Temraz 2019). Based on our results, supplementation of PJ, CM and CM $\alpha$ effectively regulated accumulation of lipid in liver and serum under the chronic alcohol intake.

It is widely known that acute or chronic alcohol intake is closely associated with excessive lipid peroxidation. Lipid peroxidation, particularly reaction of reactive oxygen species (ROS) with lipids, produces oxidative stress biomarkers, such as MDA and 4-hydroxy-2-nonenal (HNE) (Tsikas 2017). In addition, its degree is considered as an indicator of early acute hepatic damage (Ho et al. 2013). This is in agreement with our results showing that there was a significant increase in MDA levels in the serum, hepatic subcellular fractions, kidney, heart, spleen and testis in the SD rats receiving alcohol as compared with normal ones. However, supplementation of CM $\alpha$ suppressed lipid peroxidation in various organs, specifically liver (Figs. 2, 3). Interestingly, the degree of decrease in that of lipid peroxidation was significantly higher in the SD rats receiving CM $\alpha$ as compared with those receiving $\mathrm{PJ}$ and CM. In the blood stream and organ tissues, circulation and accumulation of MDA is one of the major contributions to induce oxidative stress resulting in cancer, diabetes, asthma, atherosclerosis and Alzheimer's disease (Dalle-Donne et al. 2006). Thus, our results demonstrate that administration of $\mathrm{CM} \alpha$ effectively prevents lipid peroxidation in blood and organs during alcohol intake.

Cordycepin and adenosine have been reported to show outstanding anti-oxidant and radical scavenging activities (Jiang et al. 2011). Moreover, it is presumed that bioactive compounds play an important role in preventing the oxidative damage as a dietary supplement. Several photochemical studies have identified flavonoids, phenolics and adenosine analogues as anti-oxidant ingredients isolated from CM and PJ (Yu et al. 2006). This is also accompanied by a report that $\mathrm{CM}$ and CS extracts had polyphenolic and flavonoid compounds at a concentration of 60.2 

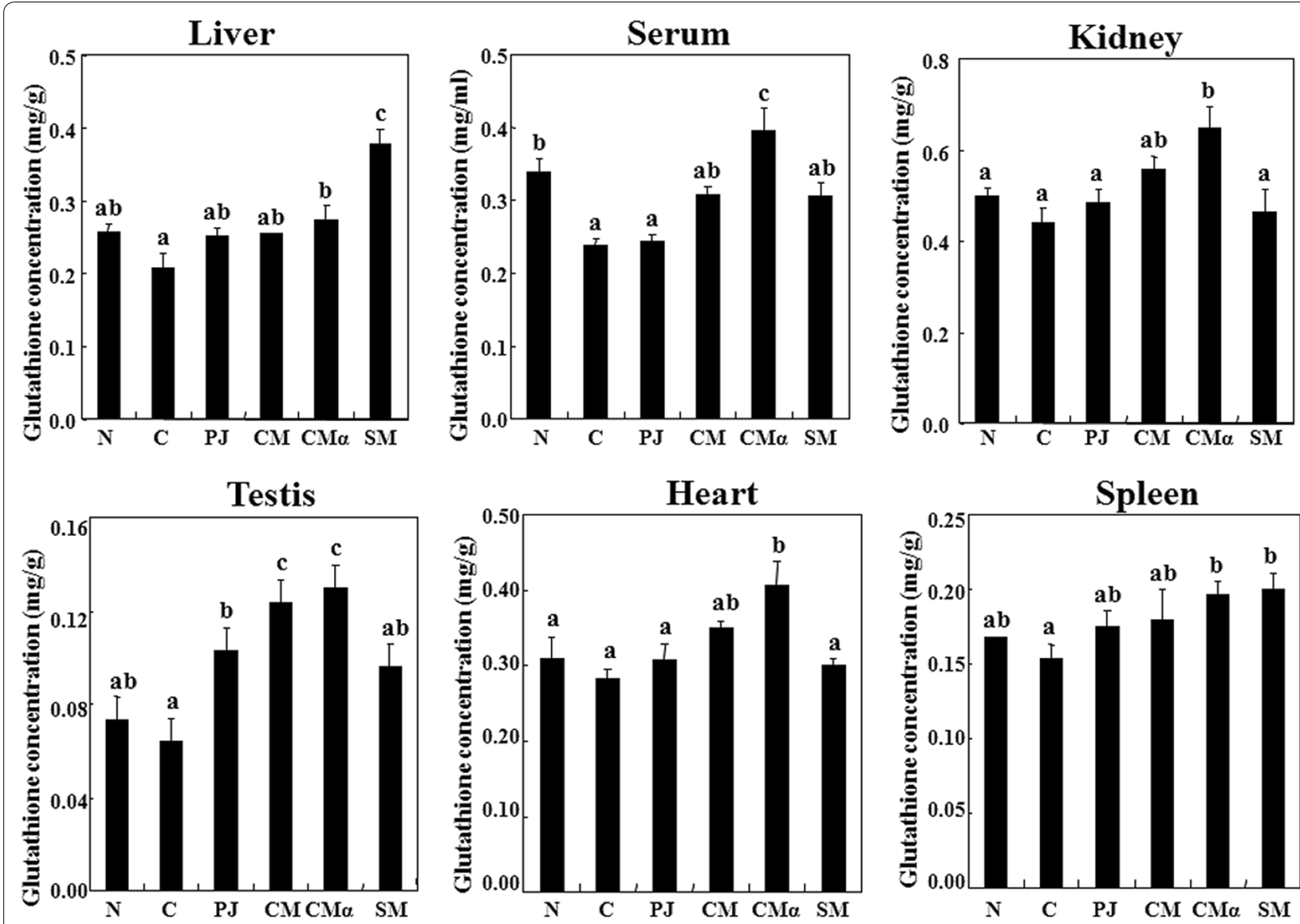

Fig. 4 Concentrations of glutathione (GSH) in the serum, hepatic homogenate, kidney, heart, spleen and testis

and $0.598 \mu \mathrm{g} / \mathrm{mL}$ and 31.8 and $0.616 \mu \mathrm{g} / \mathrm{mL}$, respectively (Yu et al. 2006). The anti-oxidant effects of CM may also arise from an abundant presence of polyphenolic compounds and cordycepin derivatives. This is also associated with a previous report showing that the ethanolic extract from fruiting bodies of CM has an anti-oxidant effect arising from a strong free radical scavenging activity (Jing et al. 2015).

Nonenzymatic anti-oxidants, such as GSH and ascorbic acid, are considered as the cellular anti-oxidant defense system against oxidative damage due to free radicals (Kurutas 2016). GSH is a major non-protein thiol tripeptide containing L-glutamate, L-cysteine and glycine in living organisms (Aquilano et al. 2014). Decreased GSH levels were also reported to arise from GSH oxidation and lipid peroxidation during alcohol metabolism (Zakhari 2013). Thus, it is involved in an endogenous defense mechanism against the peroxidative destruction of cellular membranes. In the current study, there was no significant difference in GSH levels between CM, CM $\alpha$ and normal rat groups. It showed similar tendency with MDA contents, suggesting that a lower degree of lipid peroxidation is closely associated with a higher level of anti-oxidant enzyme activity. In addition, according to our previous results, the higher cordycepin contents in $\mathrm{CM} \alpha$ can expect inducing activation of anti-oxidant enzyme (Cha et al. 2011). These results indicate that intake of cordycepin-rich CM $\alpha$ effectively blocks lipid peroxidation through regulation of the anti-oxidant enzymes.

\section{Conclusions}

Based on our results, it can be concluded that $\mathrm{CM} \alpha$ might be used as a drug and functional food in inhibiting the oxidation and hyperlipidemia in an SD model of alcoholinduced hepatic disease possibly because of cordycepin and polyphenolic compound with potential anti-oxidative and anti-hyperlipidemic activities. 


\section{Supplementary information}

Supplementary information accompanies this paper at https://doi. org/10.1186/s40643-020-00323-9.

Additional file 1. A schematic diagram of the experiment.

Additional file 2. Histopathologic findings.

\section{Abbreviations}

AlH: Alcohol-induced hyperlipidemia; CM: Cordyceps militaris; CMa: Cordycepin-rich CM; GSH: Glutathione; HDL: High-density lipoprotein; OS: Oxidative stress; PJ: Paecilomyces japonica; SD: Sprague-Dawley; SM: Silymarin; TBARS: Thiobarbituric acid-reactive substances; TC: Total cholesterol; TG: Triglyceride.

\section{Acknowledgements}

Non applicable.

\section{Authors' contributions}

HYA and YSC conceived and coordinated the study and performed the experiments. YSC validated the experimental design. HYA, HDC and YSC analyzed the experimental results. HYA, HDC and YSC wrote and edited the paper. All authors read and approved the final manuscript.

\section{Funding}

This work was supported by Korea Institute of Planning and Evaluation for Technology in Food, Agriculture, Forestry (IPET) through High Value-added Food Technology Development Program, Funded by Ministry of Agriculture, Food and Rural Affairs (MAFGA) (Grant Number 317039-4).

\section{Availability of data and materials}

All data generated or analyzed during this study are included in this article.

\section{Ethics approval, consent to participate and consent for publication} Non-applicable.

\section{Competing interests}

The authors declare that they have no competing interests.

\section{Author details}

1 Department of Biotechnology, Dong-A University, 225 Gudeok-ro Seo-gu, Busan 49315, South Korea. ${ }^{2}$ Department of Food Science, University of Arkansas, Fayetteville, AR, USA.

Received: 9 January 2020 Accepted: 16 June 2020

Published online: 19 June 2020

\section{References}

AlHajri L, AlHadhrami A, AlMheiri S, AlMutawa Y, AlHashimi Z (2017) The efficacy of evolocumab in the management of hyperlipidemia: a systematic review. Ther Adv Cardiovasc Dis 11:155-169. https://doi. org/10.1177/1753944717698925

Aquilano K, Baldelli S, Ciriolo MR (2014) Glutathione: new roles in redox signaling for an old antioxidant. Front Pharmacol 5:196. https://doi. org/10.3389/fphar.2014.00196

Bessembinders K, Wielders J, van de Wiel A (2011) Severe hypertriglyceridemia influenced by alcohol (SHIBA). Alcohol Alcohol 46(2):113-116. https://doi. org/10.1093/alcalc/agq088

Beutler E, Duron O, Kefly BM (1963) Improved method for the determination of blood glutathione. J Lab Clin Med 61:882-888

Cha JY, Cho YS, Kim I, Anno T, Rahman SM, Yanagita T (2001) Effect of hesperetin, a citrus flavonoid, on the liver triacylglycerol content and phosphati date phosphohydrolase activity in orotic acid-fed rats. Plant Foods Hum Nutr 56:349-358. https://doi.org/10.1023/A:1011884200848

Cha JY, Ahn HY, Heo SJ, Kang MJ, Lee JH, Park SH et al (2011) Improvement effect of cordycepin-enriched Cordyceps militaris JLM 0636 powder against orotic acid-induced fatty liver in rats. J Life Sci 21(9):1274-1280. https://doi.org/10.5352/JLS.2011.21.9.1274

Chen YC, Chen YH, Pan BS, Chang MM, Huang BM (2017) Functional study of cordyceps sinensis and cordycepin in male reproduction: a review. J Food Drug Anal 25:197-205. https://doi.org/10.1016/j.jfda.2016.10.020

Dahiru D, Obidoa O (2007) Evaluation of the antioxidant effects of Ziziphus mauritiana Lam. Leaf extracts against chronic ethanol-induced hepatotoxicity in rat liver. Afr J Tradit Complement Altern Med 5(1):39-45. https //doi.org/10.4314/ajtcam.v5i1.31254

Dalle-Donne I, Rossi R, Colombo R, Giustarini D, Milzani A (2006) Biomarkers of oxidative damage in human disease. Clin Chem 52:601-623

El-Tantawy WH, Temraz A (2019) Natural products for controlling hyperlipidemia: review. Arch Physiol Biochem 125:128-135. https://doi. org/10.1080/13813455.2018.1441315

Folch J, Lees M, Sloane-Stanley GH (1957) A simple method for the isolation and purification of total lipides from animal tissues. J Biol Chem 226(1):497-509

Guo P, Kai Q Gao J, Lian ZQ, Wu CM, Wu CA et al (2010) Cordycepin prevents hyperlipidemia in hamsters fed a high-fat diet via activation of AMPactivated protein kinase. J Pharmacol Sci 113(4):395-403. https://doi. org/10.1254/jphs.10041FP

Han EK, Kim YS, Yoo YS, Jung EJ, Lee JY, Chung CK (2009) Effect of artemisia capillaris and paecilomyces japonica on the reduction of hepatotoxicity and lipid metabolism induced by ethanol. J Korean Soc Food Sci Nutr 38(8):1016-1023

Heo K, Myoung KS, Lee JH, Huh CS (2009) Anti-obesitic effects of cathepsin S inhibitory fraction derived from Paecilomyces tenuipes in mice fed a highfat diet. Korean J Food Sci Technol 41(4):446-451

Ho E, Karimi Galougahi K, Liu CC, Bhindi R, Figtree GA (2013) Biological markers of oxidative stress: applications to cardiovascular research and practice. Redox Biol 1:483-491. https://doi.org/10.1016/j.redox.2013.07.006

Jiang Y, Wong JH, Fu M, Ng TB, Liu ZK, Wang CR et al (2011) Isolation of adenosine, iso-sinensetin and dimethylguanosine with antioxidant and HIV-1 protease inhibiting activities from fruiting bodies of Cordyceps militaris. Phytomedicine 18(2-3):189-193. https://doi.org/10.1016/j.phyme d.2010.04.010

Jing Y, Zhu J, Liu T, Bi S, Hu X, Chen Z et al (2015) Structural characterization and biological activities of a novel polysaccharide from cultured Cordyceps militaris and its sulfated derivative. J Agric Food Chem 63(13):3464-3471. https://doi.org/10.1021/jf505915t

Ju X, Sun Y, Cao X, Jiang J, Zhang T, Ito Y (2009) Two-step purification of cordycepin from Cordyceps Millitaris by high-speed countercurrent chromatography. J Liq Chromatogr Relat Technol 32(16):2417-2423. https ://doi.org/10.1080/10826070903188153

Koh JB, Choi MA (2003) Effect of Paecilomyes japonica on lipid metabolism in rats fed high fat diet. J Korean Soc Food Sci Nutr 32(2):238-243

Kurutas EB (2016) The importance of antioxidants which play the role in cellular response against oxidative/nitrosative stress: current state. Nutr J 15(1):71. https://doi.org/10.1186/s12937-016-0186-5

Lowry OH, Rosebrough NJ, Farr AL, Randall RJ (1951) Protein measurement with the Folin phenol reagent. J Biol Chem 193(1):265-275

McGowan MW, Artiss JD, Strandbergh DR, Zak B (1983) A peroxidase-coupled method for the colorimetric determination of serum triglycerides. Clin Chem 29(3):538-542

Nagarthna PKM, Harsha Vardhini N, Bashir Babiker, Sridhar KM (2020) Hyperlipidemia and its treatment: a review. J Adv Sci Res 11:1-6

Niharika V (2017) Introduction to hyperlipidemia and its treatment: a review. Int J Curr Pharm Res 9:6-14

Oh SW, Kim SH, Song HN, Han D (2003) Comparative chemical compositions of four kinds of tochukaso. Korean J Food Sci Technol 35(1):15-22

Ohkawa H, Ohishi N, Yagi K (1979) Assay for lipid peroxides in animal tissues by thiobarbituric acid reaction. Anal Biochem 95(2):351-358

Oliva L, Beaugé F, Choquart D, Montet AM, Guitaoui M, Montet JC (1998) Ursodeoxycholate alleviates alcoholic fatty liver damage in rats. Alcohol Clin Exp Res 22(7):1538-1543

Saini J, Goyal AK, Jangra A (2019) High-fat diet with alcohol elevate oxidative stress which cause hyperlipidemia by inducing mutation in the ANGPTL3 locus. Int J Diabetes Dev Ctries. https://doi.org/10.1007/s13410-01900773-8 
Shin KH, Lim SS, Lee SH, Lee YS, Cho SY (2001) Antioxidant and immunostimulating activities of the fruiting bodies of Paecilomyces japonica, a new type of Cordyceps sp. Ann N Y Acad Sci 928:261-273. https://doi. org/10.1111/j.1749-6632.2001.tb05655.x

Shin KH, Lim SS, Lee S, Lee YS, Jung SH, Cho SY (2003) Anti-tumour and immuno-stimulating activities of the fruiting bodies of Paecilomyces japonica, a new type of Cordyceps spp. Phytother Res 17(7):830-833. https ://doi.org/10.1002/ptr.1253

Singh D, Cho WC, Upadhyay G (2016) Drug-induced liver toxicity and prevention by herbal antioxidants: an overview. Front Physiol 6:363. https://doi. org/10.3389/fphys.2015.00363

Sun Y, Wang YH, Qu K, Zhu HB (2011) Beneficial effects of cordycepin on metabolic profiles of liver and plasma from hyperlipidemic hamsters. J Asian Nat Prod Res 13(6):534-546. https://doi.org/10.1080/10286 020.2011 .575364

Tahara M, Matsumoto K, Nukiwa T, Nakamura T (1999) Hepatocyte growth factor leads to recovery from alcohol-induced fatty liver in rats. J Clin Invest 103(3):313-320. https://doi.org/10.1172/JCl4433

Tsikas D (2017) Assessment of lipid peroxidation by measuring malondialdehyde (MDA) and relatives in biological samples: analytical and biological challenges. Anal Biochem 524:13-30. https://doi.org/10.1016/j. ab.2016.10.021
Volzke H (2012) Multicausality in fatty liver disease: is there a rationale to distinguish between alcoholic and non-alcoholic origin? World J Gastroenterol 18:3492-3501. https://doi.org/10.3748/wjg.v18.i27.3492

Yu HM, Wang BS, Huang SC, Duh PD (2006) Comparison of protective effects between cultured Cordyceps militaris and natural Cordyceps sinensis against oxidative damage. J Agric Food Chem 54(8):3132-3138. https:// doi.org/10.1021/jf053111W

Zakhari S (2013) Alcohol metabolism and epigenetics changes. Alcohol Res 35:6-16

Zhou X, Cai G, He Y, Tong G (2016) Separation of cordycepin from Cordyceps militaris fermentation supernatant using preparative HPLC and evaluation of its antibacterial activity as an NAD+-dependent DNA ligase inhibitor. Exp Ther Med 12(3):1812-1816. https://doi.org/10.3892/etm.2016.3536

\section{Publisher's Note}

Springer Nature remains neutral with regard to jurisdictional claims in published maps and institutional affiliations.

\section{Submit your manuscript to a SpringerOpen ${ }^{\circ}$ journal and benefit from:}

- Convenient online submission

- Rigorous peer review

- Open access: articles freely available online

- High visibility within the field

- Retaining the copyright to your article

Submit your next manuscript at $\boldsymbol{\text { springeropen.com }}$ 